\title{
Towards a model for planning and evaluation of the development of education for library, archive, and information services
}

\author{
Dr. Ian M. Johnson
}

\begin{abstract}
The absence of an appropriate theoretical framework for understanding and assessing influences on the development of education for library, archive and information work is reflected in a literature that is largely experiential rather than soundly grounded in empirical studies. Any development involves the introduction of innovations, and requires effective management. Drawing on theories on the management of change, the communication of ideas and the transfer of innovations, and incorporating the contextual evidence base suggested by comparative methodologies, this paper presents an analysis of the wide range of factors that need to be considered. A model developed from Porter's 'Value Chain' theory provides a framework within which these factors could be considered not only in evaluating past developments in the field, but also in planning future innovations; a model that is arguably as relevant in professional practice in library, archive, and information work as in LIS education.
\end{abstract}

\section{Author}

Dr. Ian M. Johnson is an independent researcher in the development of libraries and information services, having formerly held senior positions at the Robert Gordon University from 1989 to 2007, after previous posts in public libraries, with the British government's Library Advisers, and at the College of Librarianship Wales.

Email: i.m.johnson@rgu.ac.uk

Received 20 March 2017

Accepted 10 April 2018 
The analysis of the contributory factors and the development of the model was necessitated by a major study of development in Iraq, mainly in the second half of the twentieth century, and selective examples from that study are included to confirm the validity of the results.

\section{Introduction}

This paper had its origins in an intention to examine the body of historical evidence on the development of education for librarianship in Iraq, and particularly to consider the relationship between Iraqi and international organisations which lent itself to an analysis and evaluation of the factors that influenced the significant but hitherto little-known advances that took place there during the last half of the twentieth century (Johnson, 2016). That study identified deficiencies in the existing literature on the development of education for library, archives, and information work (LIS); considered pertinent theoretical studies in the transmission of innovation and the management of change; analysed the evidence base required for such a study and methods for evaluating it; and devised a new 'value chain' against which past and future developments could be monitored.

\section{The literature of LIS education development}

There are numerous descriptions of the history of LIS education in the developed and less developed countries. Much of the literature has, however, focused on changes in the curriculum and the implications of making them, or on the level of education at which it is desirable that the subject be taught, rather than on seeking an understanding of the broad context in which changes have taken or might take place. In LIS education, little fundamental 
attention has been given to what has influenced developments, and what should be considered to ensure that planned or necessary changes are implemented successfully and sustainably.

Much of the commentary that does exist in the field of LIS education is opinion rather than empirically based, derived from the authors' often substantial but subjective experience. This includes general guidelines on the development of professional education for librarianship and information sciences that were commissioned by Unesco (for example, Danton, 1949; Large, 1987; Neelameghan, 1978; Saunders, 1978), supplemented by guidance on emerging topics in the curriculum. The International Federation of Library Associations and Institutions (IFLA 1976; 2000; 2012) has played a similar role by publishing statements of best practice in Schools of Librarianship (SLIS). None of these guidelines were mandatory, and indeed there was no requirement for any agency or government even to consider this advice. In addition, other individuals pointed to factors likely to underpin the sustainability of SLIS in the developed (for example, Haycock, 2010; Stieg, 1992) and developing (for example, Dean 1972; Downs, 1958) countries, noting some of the challenges that the SLIS faced, without fully explaining why they existed or pointing to solutions and/or mechanisms that might be adopted to address them. The closure of SLIS in the U.S.A. and the U.K. during the 1980s prompted further discussions (for example, Haywood, 1991; Intner and Vandergrift, 1990; Ostler, Dahlin and Willardson, 1995; Paris, 1988, 1991), but these proved narrow in focusing their conclusions only on the probable causes for failure.

The LIS literature contains some notable experiential contributions about developmental issues in the less developed countries without focusing specifically on the development of LIS education. Briquet de Lemos (1979; 1981), for example, ably presented the general challenges of library development from the perspective of a less developed 
country. Gassol de Horowitz (1984) contributed an analysis of the problems and issues that librarianship as a profession needs to address in the arena of Third-World development and their implications for professional education.

During the second half of the twentieth century, early views of international development assistance undoubtedly stressed catching up with, and generally imitating, the economically advanced nations of Western Europe and North America. In countries that were less well developed in terms of archive, library, and information services, technical assistance projects established LIS services and professional education programs where none had previously existed, following models that were familiar to the donor agencies and the organisations and individuals delivering the assistance.

During the second half of the twentieth century, LIS work has been characterised not only by the ubiquitous introduction of information technology, but also by a shift in the underlying professional philosophy to give a greater emphasis to users' needs and behaviour. During this period, LIS educators in the less developed countries not only grew in numbers but also matured as teachers and as researchers. They observed the challenges faced by their former students and sought to identify solutions that would be viable in the circumstances prevailing in their country.

Inevitably, the influence of western models of library service and the relevance of aspects of western LIS education became a matter of increasing debate in the developing countries. Since the 1980s, there have been several examples of opinion-based criticisms of LIS curricula that were derived from the legacy of efforts by foreign consultants to establish or advise on the development of SLIS, or of study abroad by citizens of less developed 
countries. The American model of library education was the first to be challenged, after its introduction in Latin America (for example, Goldstein, 1982). Later, the European legacies apparent in both library services and professional education became subject to criticism in Africa (for example, Mchombu, 1986). These criticisms claimed to have focused on curricular relevance to the local environment, but did not fully explore the context in which those curricula were introduced or in which library and information services in a country had since evolved.

More recently, there have been a few formal studies that have attempted to examine library development by applying 'orientalist' or 'postcolonial' theory, a body of academic study that seeks to draw on critical theory to understand the loss of power, identity, and culture when a group of people is dominated by a powerful force (Khanal, 2012). More generally, these approaches have been criticised as the bases for so-called 'revisionist' histories, politically-biased studies that attempt to apply contemporary values to events that occurred in the past, regardless of their epistemological irrelevance.

If substantial evidence existed, the discourse analysis that provides an evidence base for these approaches could certainly be helpful in understanding the values and beliefs of European and American librarians active in less developed countries at particular points of time during their history, for example during programmes of technical assistance to modernise the economies and social fabric of countries. However, it must be acknowledged that much of the historical record of library development is so fragmented that there are few substantial collections of documents or substantial individual documents that would lend themselves to a detailed analysis of the discourse and the interaction between all the participants. This is particularly challenging in many developing countries where the 
preservation and organisation of archives is in its infancy, and where in many cases there is often little written evidence from the perspective of members of earlier, less developed indigenous societies.

After considering the literature on the development of LIS education, it was apparent that there was both scope and need for a stronger theoretical base which could be used to analyse and evaluate the factors that had contributed to library development in Iraq and provide a basis for future planning there and elsewhere.

\section{Innovation, change management, and impact evaluation}

Development - whether in a wealthy, technologically advanced society or in countries that are less well developed - can be defined as: the gradual evolution of a phenomenon to a more elaborate form; or a process in which someone or something is created or changed through the systematic application of scientific and technical knowledge to meet specific requirements. In LIS education, development is a process that may require innovation in the curriculum, in pedagogy, in the organisation and structures of the host academic institution, and in the underpinning human, technical and financial resources. By its very nature, it is a complex process which, to be successful, demands that the introduction and implementation of the requisite changes be led and managed effectively and sensitively, based on a comprehensive understanding of the issues and influences likely to be encountered.

A heightened focus on demonstrating results has increased the demand for understanding how to evaluate libraries' impact (Wavell, et al., 2002). In the field of development work, critical evaluation of projects has also become increasingly seen as 
essential, and there is a growing literature on the application of evaluation techniques. For example, Roche (1999) provided a general framework for development agencies to assess the impact of their work, and Heeks and Molla (2009) developed this further to facilitate an objective assessment of the impact of the international development agencies' current panacea — the introduction of ICTs. This approach, based on Porter's (1985) 'value chain' theory, appears to have not been used in the LIS education field. More narrowly focussed approaches, such as the Technology Acceptance Model (TAM), devised by Davis (1989), have, however, been applied to the introduction of ICTs in library and information services (for example, Izuagbe, Hamzat \& Joseph, 2016).

\section{Innovation in library and information services and LIS education}

The growing opportunities for exchange of information in a society that became increasingly mobile and technologically equipped, particularly during the second half of the last century, seem likely to have facilitated some diffusion of ideas, policies and practices in LIS work, at least as much as in any other sphere of human activity. The necessary considerations have been the subject of significant analysis by social scientists specialising in innovation theory and in management studies, building on earlier theories. The elements of change management are now well defined, yet remain insufficiently considered in the literature of LIS education.

The issues involved in managing innovative changes have been addressed in numerous studies of the transmission and diffusion of new ideas, policies, and practices in terms of their effect not only within organisations but also the society that they serve. Arensberg and Niehoff (1964), for example, argued that change would be accepted if it fitted 
into the local culture. Many of the social theorists who have discussed the management of change have focused on more tangible issues. Djelic (1998), for example, identified various pre-conditions for a successful change in social and economic arrangements:

- globalisation of roles, norms, and values

- $\quad$ existence of a cross-national agency to lead the change

- recognition of the need for change by the community subject to change.

Rogers (2003) and other communication theorists have identified the key role played by some individuals or organisations in introducing new ideas, and noted the significance of communication channels in transferring awareness and understanding of innovations. Rogers's work on the diffusion of ideas identified five characteristics that determine the rate at which changes are likely to be adopted:

- the relative advantage(s) of the new approach compared with whatever is being replaced

- the compatibility of the new approach with the needs, experiences and values of the person or group considering a replacement

- the degree of complexity in understanding and implementing the new approach

- the extent with which a new approach can be tested without a major commitment

- the visibility of the results to others affected by the new approach.

These theoretical approaches, and others not mentioned in this summary, provide some signals of issues that need to be considered by those involved in planning and 
evaluating the introduction of new ideas and practices in LIS education. However, few studies have examined the many factors influencing the adoption and acceptance of changes in library, archive and information work and the related educational programs. While the issues surrounding the transfer of ideas and practices into different contexts can perhaps be easily understood, their translation or re-interpretation, and their final transformation are more complex problems, partly because their time-frames differ; transfer can be accomplished quickly, but transformation cannot. Asheim (1966), for example, provided a reminder that heart and mind changes in librarianship may require not months but years. While he was addressing the challenges in developing countries, his remarks have a wider resonance.

\section{Change management in library and information services and LIS education}

Development of LIS education does not just happen. It is the introduction of new concepts, and changes in academic practices. Those processes must be well managed to secure the sustainability and further enhancement of the LIS program. Much of the basic elements of change management are long established. Recent studies have done little more than refine definitions.

Studies of change and innovation management focused initially on developing strategies to ensure that commercial companies remained competitive in a challenging business environment. The theoretical approaches that emerged were subsequently adapted by the public sector to facilitate a response to demands to continue to provide relevant 
services in an era when government expenditure was being restrained and society's expectations were changing.

Porter's (1980) analysis of the elements of competitive strategy stated that there are five external forces influencing change in organisations, which could be interpreted in terms of LIS education as follows:

- $\quad$ Competition - for example from other SLIS in the same or another country

- $\quad$ Entry - for example of changing technologies

- $\quad$ Substitution - for example evolution of cognate disciplines

- $\quad$ Supplier power - for example the influence of prospective students, their advisers, and sources of funding

- $\quad$ Customer power - for example the expectations of graduates, and the requirements of prospective employers

Tushman, Newman, and Romanelli (1988) developed these ideas further, observing that there are 3 types of disruption that trigger transformational change in organisations:

- $\quad$ changes in product life cycle that require different strategies

- $\quad$ changes in legal, political, economic, and technological conditions

- changes in the organisation's size, the strategy for its portfolio of products, and its executive management. 
Changes such as these were increasingly common in the information sector throughout the second half of the twentieth century (and seem likely to continue), making it imperative that SLIS acquire new competencies. Some SLIS have attempted to adapt to changing conditions by moving into new, unfamiliar areas, in a voluntary reorientation or enforced fundamental change, but many found that change came with a degree of risk.

Any innovation, such as the introduction of a new product, a change to an organisation's structure, or the implementation of a new information system has an impact on the culture of an organisation. An organisation's culture has two basic components - a set of core beliefs and values, and certain identifiable characteristics of behaviour and style which distinguish one organisation from another. Fowler (1993) noted that the objective of many organisations is to move from a static or rigid culture to one that is flexible and adaptable, exactly the challenge with which SLIS have been confronted by the introduction and spread of increasingly sophisticated digital systems in an environment that had been unaffected by such major and rapid change since the introduction of printing. Kotter and Schlesinger (1979) observed that, in a rapidly changing environment, managers needed to increase their skills in diagnosing any likely resistance to change and in choosing appropriate methods for overcoming it. Cummings and Worley (2015) noted that efforts to implement a new strategy can fail because an organisation's culture is unsuited to the change.

Porter (1985) put forward the concept of the 'Value Chain' as a means of focussing on those activities that make a real contribution to adding value to an organisation's products and services. It sets out a systematic approach for examining the value contributed by core 
ctivities related directly to the product and support activities. In the context of SLIS, these could be interpreted as follows:

\section{- Primary activities:}

- Inbound logistics (Student recruitment and enrolment, and faculty recruitment)

○perations (Teaching)

○ Outbound logistics (Graduate employment)

○ Marketing, sales, and service (Research, publication, continuing education activities, professional service)

\section{- Support activities:}

○ Human resource development (faculty development)

- Organisational infrastructure (leadership and institutional networking; internal delegation of responsibilities)

○ Technology development (learning resources - books, journals, computers, ICT network and services)

Pettigrew and Whipp (1993) noted five factors essential to accomplishing change successfully and achieving sustainability: 
- environmental assessment

- $\quad$ leading change

- $\quad$ linking strategic and operational change

- $\quad$ recognising human resources as assets and liabilities

- coherence.

Lynch (1997) noted that all products and services could be considered as a 'package of attributes'. In terms of how a SLIS might develop its ability to create and sustain an external perception of its value to its institution and to society at large, these attributes could be interpreted as follows:

- Innovation - the development of new programs, delivery formats, and research themes in response to or in anticipation of professional opinion and practices, and institutional expectations

- Exploitation - using the 'strategic assets' of the SLIS such as the knowledge base of its faculty or its technical resources to contribute to institutional, professional, and national problem solving, and continuing professional development

- Reputation - external involvement in quality assurance reviews of the product(s) of the SLIS, as well as through evaluation of the immediate and long-term experience of the graduates and their employers 
- $\quad$ Relationships - the institutional, professional, and other external networks that a SLIS establishes and nourishes to enhance the perception that the SLIS itself fosters for the relevance and quality of its product(s): programs, graduates, research outputs, and continuing education activities.

None of these activities are independent of each other, but are interdependent, and successful development of a SLIS often arises not from the activities themselves but from reinforcing the linkages between them. Porter pointed to Total Quality Management — the regular application of self-critical quality assurance and quality control processes to the activities of an organisation - as a means to achieve continual improvement of these linkages and thus the organisation's progressive development and competitive success. Total Quality Management has been applied to library management (for example, Jurow \& Barnard, 1993). Quality assurance in LIS education has been fostered in the European Union's Member States as part of the 'Bologna Process' of establishing equivalence between their higher education institutions and has become the focus of some international interest (Miwa \& Miyahara, 2015). Quality assurance in (LIS) education is based on regular internal annual and external quinquennial reviews of the currency of the curriculum and its relevance to the needs of the job market as evidenced by input from peers, employers, current students, and graduates. It is essentially a means of preventing academic atrophy, and - whilst worthwhile — has a relatively short-term focus on development and does not necessarily examine all the factors underlying change. 


\section{Putting library and LIS education development in context}

Understanding how and why education for librarianship has evolved or could be further developed clearly needs to take account of the fact that, as Foskett (1977) argued:

"The dynamics of a single system cannot be fully understood by examining that system in isolation, ... [F]or the way it functions depends on its reaction with its environment as much as on the interactions between its own parts."

The requirement then is to identify the range of evidence that would facilitate such an examination, to collect it, and to analyse and interpret it in the context of the continual development of LIS education.

Researchers in other social sciences have developed comparative methodologies to analyse the economic, political, and social contexts within which a phenomenon had evolved by examining the contextual variables to isolate and identify significant factors. Comparative studies are increasingly recognised as a key to understanding the basis of previous and current processes of constructing, organizing, and institutionalizing social and cultural orders and organizations (Siegrist, 2006).

Comparative methodology is a research technique that has been recommended for use in studies in librarianship because "it constitutes an important approach to the search for cause and effect in library development, and to the understanding of library problems" (Collings ,1971). However, the concept of comparative librarianship became confused with parallel but separate discussions about internationalisation in LIS work and education (for example, Carroll, 1970). The terms 'comparative librarianship' and 'international 
librarianship' have been used as if they were interchangeable. In reality, 'international librarianship' and 'comparative librarianship' are separate topics:

- ' international librarianship' tends mainly to comprise descriptive (and sometimes patronising) accounts of libraries and librarianship in foreign countries;

- 'comparative librarianship' seeks to produce critical, analytical and evaluative studies of library services (of the same type in the same or different countries) intended to provide not only a description of differences in their situation and an explication of the reasons for them, but also conclusions about how progress could be made within their prevailing local circumstances.

One of the advocates of comparative librarianship, Kotei (1976), pointed out that a search for causal relationships in any sphere of social organisation such as librarianship must derive from a clear understanding of the premises from which the study is being conducted. Closely allied to this, according to Jackson (1981), is understanding the information needs of the population and how these are met by existing library systems. Familiarity with library tradition and history, he argued, is also essential for understanding events. The range of background factors that have been suggested to be considered in a study of LIS education also include:

- the policies and practices of the international agencies that assisted in the development of libraries and education for librarianship

- the circumstances in the beneficiary country: 
$\circ$ the national economic, political, administrative, and cultural context within which libraries and information services evolved and operated

o the general educational and social trends

$\bigcirc$ the evolution of local publishing

$\circ$ the consequent scale and nature of library, archive, and information services

(Collings, 1970; Danton 1973; Simsova \& McKee, 1970).

However, many papers that purport to be comparative studies of libraries and librarianship conform to the criticism that Danton (1973) directed at the literature of this subfield, when he wrote that:

\footnotetext{
"most of the literature described as 'comparative librarianship' is thin, largely narrative and descriptive, and often neither comparative nor in conformity with even minimal standards of scholarly investigation..."
}

\section{Defining the Contextual Evidence for Comparative Studies of LIS}

From time to time, a few people interested in international library development have taken an interest in developing a similar theoretical approach. Several discussion papers about comparative methodologies were published (for example, Dane, 1954; Foskett, 1965; White, 1966), followed by a major textbook (Danton, 1973). However, interest in developing the theoretical underpinnings of comparative librarianship withered fairly quickly. Parker (1974) observed that the methodology of comparative librarianship remained largely untried and untested, and that remains the case today. 
Given the wide range of evidence required, much of it outwith the conventionally accepted boundaries of LIS, it is unsurprising that the application of comparative methodologies in LIS has been limited. However, as the demand for understanding the underpinning for and impact of professional developments becomes more pressing, not for theoretical reasons but to help advance the arguments for investment in services which have become more complex, the traditional boundaries within which research in librarianship has been organized may inhibit progress. The failure of its proponents to define how the results of any comparison might be evaluated has been a further constraint. Discussions of comparative librarianship appear to have paid little attention to the practicalities of presenting the results of a comparative study to meet Collings's (1971) expectation that it should explain cause and effect. Nonetheless, some indicative approaches can be seen in other attempts to evaluate complex contextual information.

Johnson's (2009) analysis of information behaviour states that any context has three facets, including the situation in which individuals are immersed, actions that have specific effects on events, and significant frameworks such as belief systems.

The role of management and the way in which the role of each functional managerial position was carried out had been identified by Rockart (1979) as one element in a framework of Critical Success Factors (CSFs) for defining areas where high performance in information acquisition and use is required to achieve a goal, to resolve a problem or, as in this study, to validate assumptions (Bullen \& Rockart, 1981). Gladwell (2000) emphasised the need to focus on individual actors or groups of actors, and their perceptions of events, as previously recommended by Hitchcock and Hughes (1995). This was reinforced by Rogers's (2003) views on the way in which a few key individuals can have a significant influence as 
opinion leaders and change agents. Such individuals need the skills of persuasion, and need to be well-connected, with a wide personal communication network that includes the influential people in their sector of society. Thus, they can have a strong influence in identifying opportunities for promoting change and taking a new product or service beyond a 'tipping point'.

Gladwell (2000) also observed that getting a 'social epidemic' started involves transferring ideas through differing groups in society — those defined by students of the communication of ideas as innovators, early adopters, the early majority, the late majority, and finally the laggards. The first two groups are visionaries and risk takers, whereas the majority avoid risks and are pragmatists.

Other elements of Johnson's (2009) 'context' are susceptible to the closer focus offered by applying the taxonomy known as S.T.E.P. - Social, Technical, Economic, Political — first devised by Aguilar (1967) for evaluating the results of any environmental scanning undertaken to define the situation in which individuals or institutions are immersed as part of the strategic planning function. It accords with elements (for example social background, communication media, economy, politics) identified by Danton (1973) and others as influencing library development. Some of Aguilar's terms are open to wide-ranging definition. For example, 'Social' could be interpreted to include factors such as education and literacy, while 'Economic' could refer to the state of the national economy, the funding allocated to institutions, or personal incomes. 'Political' could be taken to include governance and legal issues, while 'Technical' could refer to the publishing industry as well as the new Information and Communication Technologies. Notwithstanding this semantic inexactitude, these are important elements, as emphasised by Rockart (1979), that must be understood in 
assessing how the development of a SLIS takes place or may be shaped against a background of environmental changes over which it may have little control.

Rockart also identified two other factors which lend themselves to adaptation for the purpose of this kind of research. He noted that each institution, i.e. each SLIS, has a sub-set of CSFs that are determined by the characteristics of the information sector in the country that it serves. Among these, he noted that the optimal strategy of an organisation is defined by its individual situation determined by its geography, history, and current competition (Bullen \& Rockart, 1981; Rockart, 1979). In doing so, he concurred with Danton's (1973) statement that the analysis should recognise the geographic situation of the subject being studied, the history of library development in the locality, and interaction with external agencies and movements.

Johnson's (2009) comment on the significance of frameworks such as belief systems reinforced Buckland and Gathegi's (1991) argument, which stressed that effectiveness in research and theory development requires accounting for such contextual factors as differences in culture and language. Danton (1973) had also earlier referred to a wider range of factors that included race, ideology, and religion.

Johnson's (2009) taxonomy did not, however, address the temporal element implicit in any historical study of changes. This had been identified by Rockart as one of the CSFs, noting that there are areas of activity which become critical for organisations at particular points in time (Rockart 1979; Bullen \& Rockart, 1981). Rockart's initial concept was subsequently affirmed in Rogers's (2003) definition of the five stages through which innovation occurs — knowledge, persuasion, decision, implementation, and confirmation, 
and Gladwell's (2000) discussion of how innovations occur and become embedded. It was further extended by Shachaf's (2003) modelling of the life cycle of some LIS activities. She showed how these evolve through stages, which can be redefined in terms of the development of LIS training and education as:

- The Embryonic Stage. Recognition of the need for training is the initiating force, sometimes characterized by informal, voluntary training activities. These efforts provide the basis upon which a committee of academic leaders and other stakeholders can begin to work towards setting up formal programs.

- $\quad$ Early Development. The best curriculum and syllabi that fit the local context are defined. The likely faculty members undertake intensive assessment of comparable developments and locally available resources, and work through the funding arrangements.

- Development. Efforts are focused on securing the funds and learning resources to secure the viability of the program, and on establishing pedagogical effectiveness and efficiency in its delivery.

- Maturity. The program is stable, with a clear identity and clear boundaries. This stage can exist for many years, during which minor changes in faculty, syllabi, resources, and budgets may occur. Quality assessment and statistical measurements are employed to continually evaluate the program and guide its development.

- Enhancement. Advanced programs, research, and continuing education activities are introduced. Faculty take a leading role in development of the profession locally and nationally. 
- Disbanding. Disbanding could follow any of the stages of development if program viability weakens for any reason (adapted from Shachaf, 2003).

Gladwell (2000) observed that 'tipping points' occur when those actions stimulate a transition from one situation to another. After the 'tipping point' is reached, successful ideas, products and services begin to be adopted quickly, and behave as 'epidemics'. Johnson (2009) also referred to actions that have specific effects on events.

\section{Method: Devising a checklist for evaluation}

The aim of this study was to focus on the development of LIS education in Iraq since its inception, and acknowledged that a new approach to evaluation was needed. In some senses, the approach that was developed for this study may be compared to the development of grounded theory in eliciting theories and propositions directly from data or information, while recognising that circumstances — both historical and contemporary - may prohibit testing the hypothesis that emerges.

The need was to develop a framework which could be used to focus a review of the evidence. The first step was to analyse and summarize the elements in the management of change, in the diffusion of concepts and practices, and in the context within which LIS exists. Although the terminology sometimes differed, many of the factors identified in the studies examined proved to be similar. These were summarised within key groups that emphasised the study's focus on LIS development, and the terminology was adapted, when necessary to make it more familiar to readers accustomed to the terminology of LIS. A provisional checklist is presented in Table 1. 


\begin{tabular}{|c|c|}
\hline $\begin{array}{l}\text { Key elements underpinning } \\
\text { education for information }\end{array}$ & $\begin{array}{l}\text { - The scale and nature of library, archive, and } \\
\text { information service provision } \\
\text { - Governance and funding of educational institutions } \\
\text { - Human resources - students, teachers } \\
\text { - } \quad \text { Learning resources } \\
\text { Teachers' knowledge and skills, beliefs, and values }\end{array}$ \\
\hline $\begin{array}{l}\text { The situation in which the } \\
\text { information sector is immersed }\end{array}$ & $\begin{array}{l}\text { - } \quad \text { Local traditions, culture, language, race, and religion } \\
\text { - } \quad \text { Gonomic context } \\
\text { - } \quad \text { Information needs } \\
\text { - } \quad \text { Trends in education and literacy } \\
\text { - } \quad \text { Other social trends } \\
\text { - } \quad \text { Publishing and the book trade } \\
\text { - } \quad \text { and ICTs } \\
\text { - International relations } \\
\text { - } \quad \text { Globalisation of professional norms, roles, and } \\
\text { - } \text { somparators, for example cognate disciplines, and } \\
\quad\end{array}$ \\
\hline $\begin{array}{l}\text { Events, actions, and other } \\
\text { factors that have specific effects } \\
\text { in mobilising change in the } \\
\text { information sector }\end{array}$ & $\begin{array}{l}\text { - } \text { Connections and interaction among people and } \\
\text { - Rovements } \\
\text { - Reflection on unfamiliar problems } \\
\text { - Relative advantage(s) of change(s) perceived } \\
\text { - Voluntary reorientation or enforced fundamental } \\
\text { - } \text { change } \\
\text { - Policies and practices led by international agencies } \\
\text { - } \quad \text { and/or legislative action } \\
\text { - Areas of activity becoming critical for organisations } \\
\text { - } \quad \text { strategies shaped by organisational or institutional } \\
\text { - expectations } \\
\text { - Emergence of alternative services and suppliers } \\
\text { - Evolution of cognate disciplines } \\
\text { - Coed to build or maintain reputation } \\
\text { - Leadership instilled by attitudes and experience of } \\
\text { an individual, or defined by the role of each } \\
\text { - functional managerial position } \\
\text { - Actions prompted by recruitment of new staff, } \\
\text { including changes in executive management } \\
\text { - Staff development } \\
\text { Exploitation of 'strategic assets' }\end{array}$ \\
\hline
\end{tabular}




\begin{tabular}{|c|c|}
\hline $\begin{array}{l}\text { Overcoming resistance to } \\
\text { change in the information } \\
\text { sector }\end{array}$ & $\begin{array}{l}\text { Recognising the degree of complexity of the } \\
\text { proposed change(s) } \\
\text { Assessing compatibility of change(s) with needs, } \\
\text { experiences, and values of all those affected } \\
\text { Making the likely results of change(s) visible to all } \\
\text { affected } \\
\text { Building a network of supportive and influential } \\
\text { relationships }\end{array}$ \\
\hline $\begin{array}{l}\text { Recognising when innovations } \\
\text { become embedded in the } \\
\text { information sector }\end{array}$ & $\begin{array}{l}\text { - Historical boundaries which allow for definition } \\
\text { - Existence of innovators, early adopters, majority } \\
\text { adopters, and laggards } \\
\text { - Existence of a secondary set of 'connecters' } \\
\text { - Tipping point(s) }\end{array}$ \\
\hline
\end{tabular}

Table 1: A provisional checklist for reviewing the development of education for

\section{librarianship, information science, and archives and records management}

The development of the checklist underpinned a critical reading of the historical account, seeking evidence of the presence of one or more of these factors. Although such a wide range of variables complicates investigation and theory development, ignoring them entails the risk of producing irrelevant results. This checklist is an ideal tool for analysing issues because the factors listed are not a standard set of measures but can be related to the specifics of a particular situation and can thus be used even in a single case study. They are not dependent on the availability of quantitative data and accord with the principal elements of comparative studies in focussing not only on events, but also on the related circumstances, as well as taking account of the role played by individuals. They can be used to condition the analysis, to highlight the linkages, if any, between these contextual factors and events or actions, and explain the conditions under which they may apply.

In some respects, the approach adopted for this study is similar to Qualitative Comparative Analysis (QCA), part of a new generation of theoretical approaches to assessing 
causality and impact, originally developed from the late 1980s onwards to undertake complex comparisons of countries or societies (Ragin, 1987). QCA is aimed at meeting the needs of development agencies and their appointed service providers for informing the providers of the funding and the intended beneficiaries of the impact of a project. QCA seeks connections between influencing factors (or 'conditions') and outcomes. It assumes that multiple 'conditions' can lead to the same outcome, and that a single 'condition' does not usually produce an effect on its own. Rather, it acknowledges that 'conditions' interact and combine to produce an effect, as is accepted in comparative methodology generally (Schatz \& Welle, 2016). QCA requires in-depth qualitative knowledge of each case, which is obtained using a range of qualitative research methods such as ethnography, semi-structured interviews, observation, or literature reviews, as well as quantitative data from surveys, etc. It seems more suited to conducting an analysis of the immediate outcome(s) of a specific development project than to undertaking a historical study of longer-term development policies and activities for which all these types of evidence may not always be available.

\section{Comparison in a single case study}

Although this was to be in effect a single case study, it was recognised that, for comparative purposes, something akin to a control group could be offered to strengthen the analysis by examining the same or similar phenomena in differing circumstances:

\footnotetext{
"The essence of the method is the examination of the ways in which a subject has been treated in several various circumstances, to discover first what have been the similarities, and second what have been the differences; and to learn, particularly from the difference, how the subject may be pursued in the future." (Foskett, 1980)
} 
In the study for which this approach was developed, one comparator was sought in the developments in the cognate field of archives studies. In the context of Iraq, where legacy collections of archives of international importance are to be found, comprising the records of the numerous administrations as well as of the beliefs and scientific systems of several societies that predominated during the country's history, the choice of this discipline had a particular resonance. In a wider context, it was also relevant because of the movement towards the harmonisation of education for librarianship, information science and archives studies that was taken up and promoted by Unesco in the last quarter of the twentieth century. This approach proved useful because the development of archives studies was fostered in an entirely different manner from mainstream LIS education, and achieved different results. This served to underpin the conclusions.

Another comparator that was identified is the broader regional context. During the second half of the twentieth century, various national and international agencies provided support to underdeveloped nations for the development of library and information services and education for librarianship. When studying the technical assistance that was provided to individual countries such as Iraq, an understanding of the main trends in agencies' approaches to LIS development problems and the relevance and effectiveness of their policy guidance in the Arab world could provide an external benchmark for their activities and impact in Iraq. Therefore, where appropriate, activities influencing other Arab states or developments taking place in them during these periods were also considered. The aim of noting comparable developments in the Arab world was not to be exhaustive, which would have been impracticable. It was in keeping with the use of the other comparators, which it must be emphasised, were intended solely to draw attention to circumstances or events that 
illustrated Iraq's relative situation, the influence of external peers, or its distinctive response. Nonetheless, the differences in progress between Iraq and the other Arab states facilitated a discussion of the underlying causes.

Moreover, taking note of the importance of the temporal element in development, the study acknowledged that there were several distinct points during the twentieth century when there were events in the history of Iraq that defined the boundaries of periods during which the country was subject to a specific set of political or economic circumstances. This made it possible to test the factors identified in Figure 1 against differing conditions. This effected a continual review of the evidence, as recommended by Creswell (2003), presented in the context of each identifiable period or stage in the development of education for librarianship, and facilitated a final, summary discussion of these themes. The analysis thus reflected varying challenges and opportunities that arose in each period, and moderated the force of the overall, summary conclusions.

\section{Assembling the evidence}

Assembling the evidence for a comparative study such as this can be demanding. Some preliminary information gathering and reflection had taken place throughout the author's career. However, the main effort committed to searching for, reviewing, synthesising, and organising the highly fragmented sources of information relevant to this study of LIS education development in Iraq was an intermittent activity over a ten-year period. The intensity of activity varied during that time, being dependent on the author's ability to travel to access the collections of several libraries and archives in both Britain and the U.S.A., as well as the Unesco archives and library in Paris, and the Gulbenkian 
Foundation archives in Lisbon. In addition to the range of previously unexplored archival material that was discovered, the literature search (which demonstrated how little of the LIS literature is recorded by the published indexing services, as well as requiring exploring literature beyond the boundaries of LIS) led to more than 4,000 journal articles, books and theses being examined for relevant material. The result was a coherent and contextualised historical account of the development of LIS and related education and training Iraq, which provided the evidence base for an examination of the contributory factors identified in the checklist.

Because the possible significance of actions by individuals or their influence on events was clearly relevant to the study, some effort was put into researching their biographies to facilitate a prosopographic analysis of common characteristics that might be significant (Keats-Rohan 2007). Because most of the individual involved had not been the subject of published biographies, this research was necessarily largely web-based and timeconsuming. Although the results proved uneven in range and depth, preventing the planned analysis, the evidence that emerged proved valuable in suggesting factors that had shaped some of their individual contributions to development.

None of the factors identified in this study could be said to be independent of the others. In broad terms, the development of LIS education can be seen to be a consequence of interaction, illustrated in Figure 1, between:

- $\quad$ SLIS - their number, size, resources, institutional environment, etc.

- Prevailing national circumstances - the economy, government, education, publishing, library and information services, culture, etc. 
- The international environment - international associations and donor agencies - policies, advice, resources, priorities, etc.

- The temporal framework - current state of development.

- $\quad$ Specific actions

\section{SLIS}

International environment

Temporal framework

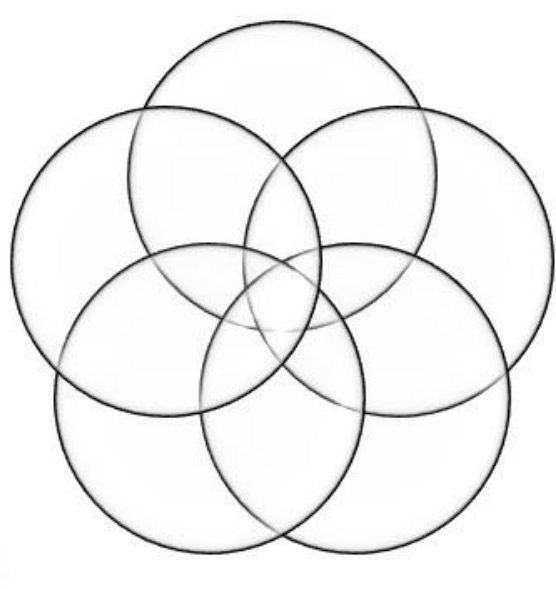

\section{National circumstances}

Actions

Figure 1: Interactions in the development of LIS education

\section{The 'Value Chain' in library and LIS education development}

Porter's (1985) ‘value chain’ concept goes beyond demonstrating the merits of understanding how various factors interact to explain how progress takes place. The 'value chain' has long been acknowledged as a useful approach to library management (for example, Cronin \& Davenport, 1988). Such an approach was developed to assess the impact of ICTs in development (Heeks \& Molla, 2009). However, there appeared to have been no previous attempt to outline a 'value chain' for the development of LIS education. This suggested the 
need for the development of a 'value chain' model for the development of LIS education through which a program can be seen to evolve.

This model presented here was adapted from the model developed by Heeks \& Molla, (2009) and incorporated elements from the 'balanced scorecard' approach to measuring progress towards objectives that was popularised by Kaplan and Norton (1992). The resulting model, outlined in Figure 2, appears valid whether establishing a new SLIS or a new program within an existing SLIS (or indeed any developmental activity in the library and information field). Each stage demands careful preparation, assessment, and follow-up, as can be seen in the brief critique of some aspects of the evolution of the LIS programs in Iraq which appears later in this paper.

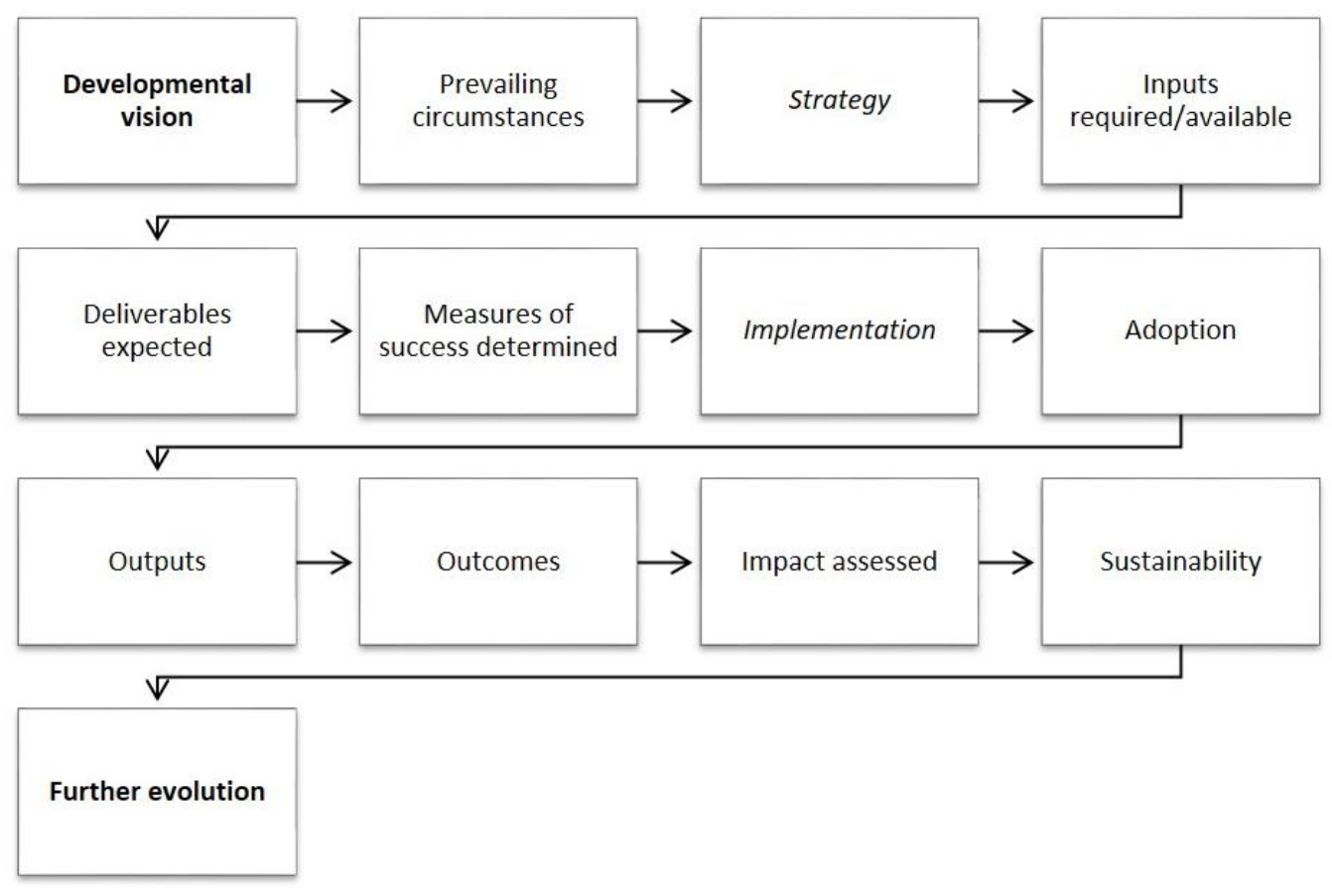

Figure 2: The development of LIS education - a 'value chain' model 


\section{Discussion: the potential of the checklist}

The study confirmed the validity of most of the generic factors shown in Figure 1. It also illuminated the interplay between them, as illustrated in Figure 2. Although this paper is intended principally to outline the method that was developed, it seems appropriate to repeat here some of the key conclusions that emerged, to illustrate the potentiality of the approach.

Before international technical assistance was sought by and offered to the libraries of Iraqi institutions at the beginning of the second half of the twentieth century, library staff development appeared to have been little more than on-the-job training to inculcate practices that had evolved over several thousand years. The subsequent development of the human resources needed by the continual expansion of Iraq's library, archive, and information services to support changes in the country's economy and society evolved through a pattern commonly experienced in developing countries, beginning with short training courses by foreign experts. The education and training that they offered was necessarily based on the then current understanding of LIS principles and practices in the wealthy industrialised countries. The experts' mostly short-term assignments offered little opportunity for investigating the local situation, adapting to it, and developing relevant learning resources. These were complemented or followed by overseas professional education for a small number of nationals of the country concerned, which was subject to the same constraints on its content and thrust as the short in-country courses taught by consultants. The eventual initiation by a local academic institution of a program offering formal qualifications taught by local teachers was often guided by foreign consultants. The teaching largely relied on an initially small cadre of local librarians who had been exposed to one-year programs in foreign institutions that, although aware of and often sympathetic to the particular needs of foreign 
students, were necessarily primarily focused on preparing graduates for their home market. The overseas programs, usually only one-year of study, gave little opportunity for the foreign students to reflect on its relevance and how it might be adapted to their home country's circumstances.

Despite increasing numbers of professionally educated personnel, their role in developing a more locally relevant curriculum was constrained by the still limited capacity to investigate the local situation and to produce the learning materials that students would need. At the same time, student motivation towards professional education and practice and activities was often inhibited by the status of LIS education within the overall higher education system, and by the inadequacy of local library services as demonstrators of appropriate practices. Moreover, the way in which LIS development in Iraq was both fostered or inhibited by prevailing economic and political circumstances was repeatedly demonstrated, conforming to Gladwell's (2000) postulation that 'social epidemics' are sensitive to prevailing conditions.

During the 1970s, the development of LIS education in Iraq was fostered by taking advantage of the strong economy and the government's educational aspirations, and a large cadre of teachers with foreign LIS qualifications was assembled. However, advisory services for library users remained seriously underdeveloped, reflecting the government's inability, because of pressure on its resources from a growing population, to encourage pedagogies and develop local publishing in a way that would have fostered a culture of independent reading and critical enquiry. 
When Iraq was impoverished by the long war with Iran in the 1980s and the U.N. embargo in the 1990s, external assistance ceased. LIS education was able to continue to evolve only through purely indigenous efforts, providing an alternative to study abroad in meeting the country's requirements for trained personnel. Despite the declining state of its library and information services, Iraq's LIS educators made strenuous efforts to overcome limits on their access to new professional knowledge and took the opportunity to introduce advanced programs that responded to the government's need for in-country Master's and Doctoral programs, and enabled some information professionals' aspirations for higher status to be fulfilled.

The earlier impact of participation in foreign consultants' efforts to develop LIS education by a steadily growing and carefully managed group of Iraqi demonstrators and teachers certainly seems to have fostered a collective will amongst them to seize the opportunities presented by national circumstances to evolve study programs at higher levels that demonstrated the substance of librarianship and information studies as an academic discipline. Here we see conformity with Gladwell's (2000) focus on the 'Law of the Few', which asserts that a few key individuals can have a significant influence on initiating change and taking a new product or service beyond the 'tipping point'. Indeed, the whole study repeatedly pointed to the pivotal role played by individuals, both foreigners and Iraqi nationals.

The policy guidance and practical inputs from the development agencies for the development of archives and records management was significantly less than for librarianship and information studies, partly because the agencies did not have relevant in-house expertise for much of the same period. The failure to ensure adequate records management in Iraqi 
institutions can be largely attributed to this lack of commitment by the agencies.

Significantly, in a country that has a wealth of collections of ancient records and literature in various formats, the introduction of graduate education for archives management has been only recent, the result of a domestic initiative by academic historians.

The evidence from the study pointed to a degree of collaboration between the various national and international agencies, but it appears to have occurred incidentally, i.e. only when organisational goals coincided and were compatible. Sharing of experience on an ad hoc basis was commonplace among individuals and sometimes organisations who were contemporaneously engaged in the provision of technical assistance in the country. However, there was little sharing of long-term planning between states or institutions, or even between the specialised agencies of the United Nations (despite the broad policy directions that the U.N. issued from time to time, many of which were sometimes also adopted by bi-lateral agencies). Underlying reasons for this appear to have been the differing aims and policies of the donor agencies, derived from their experience of differences in the state of development of the beneficiaries and their capacity to absorb assistance, and differences in their capacity to respond at particular junctures.

In one sense, the research demonstrated the obvious - that the development of LIS education is directly related to the growing number and diversity of information services in Iraq. However, it also highlighted the extent to which development of LIS education reflected the constraints and opportunities presented by domestic circumstances. It pointed to a need for greater political awareness and leadership skills, not only on the part of the educators themselves, but also in what they transmitted to their students about their wider environment and how they should and could actively shape it. 


\section{Discussion: the potential of the 'Value Chain'}

The first stage of initiating any 'vision' for development must be an assessment of all the 'prevailing circumstances'. It is clear that, from the early 1950s, Unesco sought to set up a School of Librarianship in Iraq, without any understanding of even local library services or academic conditions - a failing that Ballard (1980) noted as a typical feature of efforts to develop LIS education. The Iraqi authorities initially resisted this, perhaps because they recognised the situation, or did not consider it a national priority. When it suited their purposes, it was prioritised. Unesco then agreed that the Iraqi request to allocate Participation Programme funds matched the Organization's aims, and eventually went further in securing substantial support from UNDP.

Unesco's strategy, constrained by the limited 'inputs' that it could provide because of its regular budget and the human resources available, was (and still appears to be) to undertake projects that, while providing a demonstration of modern library services, were also expected to adapt to local needs and circumstances and not impose a foreign model, acting as a "center for research and experimentation in the adaptation of methods of library service to the local conditions of the region" (Evans, 1954). Setting aside the fact that its first project in Iraq was based on a false premise, its strategic vision was limited. It recognised the need for in-service training and for some staff to be offered the opportunity to attend an LIS education program in an advanced country, but reporting of the project was terse, uncritical, and probably enjoyed a very limited distribution, thus failing to communicate how the results of the experiment might be adapted to act as a model for other countries. These problems continued to be evident in later projects, even when substantial funds might have been available from UNDP. Indeed, the scale of UNDP funding and the lack of clarity that these 
were still essentially experimental or demonstrator projects may have raised Member States' expectations about the universal availability of general developmental assistance from Unesco. The Ford Foundation's strategy, which included a large number of scholarships to study in the U.S.A. for Iraqi counterparts expected to take over from the specialists seconded by the Foundation, appears to have been more soundly based and better resourced, but is also open to criticism for the absence of any public reports on its specialists' activities.

All the specialists provided by Unesco and the Ford Foundation carried out their tasks, but the 'deliverables' from the early Unesco consultants' missions were not defined beyond the 'implementation' of their assigned tasks, and the legacy from their activities was probably somewhat insecure. On the other hand, seemingly on their own initiative, the Ford Foundation's specialists also encouraged further development by beginning to engage Iraqi librarians in delivering in-service training, which enabled later Unesco consultants to develop a core team of LIS teachers as formal programs were 'adopted' and evolved.

The 'outputs' from these new programs went some way towards meeting the manpower shortages created as Iraq's library and information services grew. However, the resulting 'outcomes', the benefits in terms of the contribution that modern library services could make to national development, were frustrated by the vacuum in which they existed, because the prevailing circumstances did not include a national strategy based on meaningful manpower planning, fostering the local publishing industry, and encouraging a culture of independent reading.

Any assessment of the 'impact' of development activities would need to take account of why the activity was initiated; at whom was it targeted; and the form it took. It is possible 
to conclude that the Iraqi LIS teachers had developed their own vision and a strategy for program development based on a shared set of values, and had implemented significant changes in the programs and services that they offered. Their progress was inhibited by the financial circumstances that they faced during the last decades of the twentieth century, and the limitations that were placed on their continuing professional development, particularly in gaining the advanced degrees that would have enhanced their knowledge, skills, and academic standing. The organisational culture of Iraqi higher education - a rigid bureaucracy — was also a hindrance to progress, and perhaps one that revealed limitations in the networking and advocacy skills of the LIS educators and the graduates from their programs.

\section{Conclusion}

This study examined the planning and evaluation of the development of library, archival and information provision in a single country and the professional and technical education that underpins it. Previous studies of the international assistance for the development of libraries and LIS education by, for example, Brewster $(1974 ; 1976)$ and Keresztesi (1977) had pointed to the need for a methodology that would enable development to be explored in greater depth so that future efforts to develop a self-sustaining education program could be more securely based.

The clear indications from this study are that development is not a simple process. It confirmed the relevance of a wide range of factors suggested by theories of change management and the transfer of innovations that need to be continually kept under review throughout the planning, implementation, and evaluation of any innovation in the field. It has 
validated the relevance to the development of the information sector in general and education for information in particular of the contextual factors identified in the theories of comparative librarianship. In an extensive case study of development in Iraq in the latter half of the twentieth century, it showed that this wide range of insights is needed to underpin a balanced evaluation of the outcome of earlier development activities in education for library, archives, and information work.

The study also outlined and considered a provisional 'value chain' model that could offer a useful framework not only for the evaluation of past developments, but also for the guidance of future managers, planners, and development agencies seeking to achieve successful and sustainable development in the field. Much of the evidence presented in the study reflected how the development of library, archive, and information services and of the related professional and technical education are inter-twined. This suggests that most of the factors in the checklist produced for this study may be as relevant in evaluating and planning changes in professional practice as in LIS education.

This study was the first attempt to provide such a comprehensive theoretical base for planning and evaluating the development of library, archival and information provision in a country and the professional and technical education that underpins it. It is recognised that further, similarly detailed national case studies may reveal additional factors.

\section{References}

Aguilar, F.J. (1967). Scanning the Business Environment. $6^{\text {th }}$ ed. New York: Macmillan. Arensberg, C.M., \& Niehoff, A.H. (1964). Introducing Social Change: A Manual for Americans Overseas. Chicago: Aldine Publishing Co. 
Asheim, L. (1966). Librarianship in the Developing Countries. Urbana: University of Illinois Press.

Ballard, R.M. (1980). Library Education and Library Problems in Developing Countries. International Library Review, 12(1), 65-70.

Brewster, B.J. (1974). An Analysis of American Overseas Library Technical Assistance, 1940-1970. (Doctoral dissertation,) University of Pittsburgh.

Brewster, B.J. (1976). American Overseas Library Technical Assistance, 1940-1970. Metuchen, NJ, USA: Scarecrow Press.

Briquet de Lemos, A.A. (1979). International Programmes: Impact and Implementation in Developing Countries, with Discussion. In Burnett, D. \& Cumming, E. E. (Eds.) International Library and Information Programmes: Proceedings of the Tenth Anniversary Conference of the International and Comparative Librarianship Group of the Library Association, University of Loughborough, September $23^{\text {rd }}-25^{\text {th }}, 1977$, pp. 6889. London, UK: Library Association.

Briquet de Lemos, A.A. (1981). A Portrait of Librarianship in Developing Societies. Urbana: University of Illinois at Urbana-Champaign, Graduate School of Library and Information Science. Occasional Paper no. 148.

Buckland, M.K., \& Gathegi, J.N. (1991). International Aspects of LIS Research. In McClure, C.R. \& Hernon, P. (ed.) Library and Information Science Research: Perspectives and Strategies for Improvement (pp. 63-71). Norwood: Ablex..

Bullen, C.V., \& Rockart, J.F. (1981). A Primer on Critical Success Factors. Retrieved from: https://dspace.mit.edu/bitstream/1721.1/1988/1/SWP-1220-08368993-CISR-069.pdf 
Carroll, F.L. (1970). The Development of an Instrument for the Evaluation of Internationalism in Education for Librarianship. (Doctoral dissertation), University of Oklahoma.

Collings, D.G.W. (1970). Outline for the Study of a Foreign Library System. In Simsova, S. \& McKee, M. (ed.) A Handbook of Comparative Librarianship (pp. 400-403). London: Bingley.

Collings, D.G.W. (1971). Comparative Librarianship. In Kent, A., Lancour, H., \& Nasri, W. (ed.) Encyclopedia of Library and Information Science, Vol. 5 (pp. 492-502).. New York: Marcel Dekker.

Creswell. J.W. (2003). Research Design: Qualitative, Quantitative and Mixed Methods Approaches. $2^{\text {nd }}$ ed. London: Sage Publications.

Cronin, B., \& Davenport, L. (1988). Libraries and the University Value Chain. In PostProfessionalism: Transforming the Information Heartland (pp. 167-171). London: Taylor Graham..

Cummings, T.G., \& Worley, C.G. (2015). Organization Development and Change. $10^{\text {th }} \mathrm{ed}$. Andover: Cengage Learning.

Dane, C. (1954). Comparative Librarianship. Librarian and Book World, 43(8), 141-144.

Danton, J.P. (1949). Education for Librarianship. Paris: Unesco.

Danton, J.P. (1973). The Dimensions of Comparative Librarianship. Chicago: American Library Association. 
Davis, F.D. (1989). Perceived Usefulness, Perceived Ease of Use, and User Acceptance of Information Technology. MIS Quarterly, 13(3), 319-340.

Dean, J.E. (1972). Planning Library Education Programmes: A Study of the Problems Involved in the Management and Operation of Library Schools in the Developing Countries. London: Andre Deutsch.

Djelic, M.L. (1998). Exporting the American Model: The Postwar Transformation of European Business. Oxford: Oxford University Press.

Downs, R.B. (1958). How to Start a Library School. ALA Bulletin, 52(6), 399-405.

Evans, L.H. (1954). Unesco Work and Method Illustrated by the Library Programs. In Carnovsky, L. (ed.) International Aspects of Librarianship (pp. 12-20). Chicago: Chicago University Press.

Foskett, D.J. (1965). Comparative Librarianship. In Collison, R.L. (ed.) Progress in Library Science, 1965 (pp. 125-146). London: Butterworths.

Foskett, D.J. (1977). Recent Comparative and International Studies in Non-Library Fields. In Harvey, J.F. (Ed.) Comparative and International Library Science (pp. 15-30). Metuchen: Scarecrow Press.

Foskett, D.J. (1980). Discovery of Essence: An Enquiry into Comparative Librarianship. In Bloomfield, B.C., \& Pearson, J.D. (Eds.) Middle East Studies and Libraries: A Felicitation Volume for Professor J.D. Pearson (pp. 59-68). London: Mansell.. Fowler, A. (1993). How to Manage Cultural Change. Personnel Management Plus, 4(11), 2526. 
Gassol de Horowitz, R. (1984). Graduate Education for Librarianship in Venezuela: A Theoretical Framework. (Doctoral thesis) University of California, Berkeley.

Gladwell, M. (2000). The Tipping Point: How Little Things Can Make a Big Difference. Boston: Little Brown and Co.

Goldstein, E. (1982). Transferability of American Library and Information Science Education to Mexico. In Petrarca, A.E., Taylor, C.I., \& Kohn, R.S. (Eds.) Information Interaction: Proceedings of the 45 ${ }^{\text {th }}$ ASIS Annual Meeting, Columbus, Ohio, 17-21 October 1982 (pp. 116-118). White Plains: Knowledge Industry Publications, Inc.

Haycock, K. (2010). Predicting Sustainability for Programs in Library and Information Science: Factors Influencing Continuance and Discontinuance. Journal of Education for Library and Information Science, 51(3), 130-141.

Haywood, T. (1991). Changing Faculty Environments. Birmingham: Birmingham Polytechnic, Faculty of Computing and Information Studies.

Heeks, R., \& Molla, A. (2009). Impact Assessment of ICT-for-Development Projects: A Compendium of Approaches. Manchester, UK: University of Manchester, Global Development Institute. Retrieved from: http://www.gdi.manchester.ac.uk/research/publications/other-working-papers/di/di-wp36/

Hitchcock, G., \& Hughes, D. (ed.) (1995). Research and the Teacher. $2^{\text {nd }}$ edition. London: Routledge.

International Federation of Library Associations and Institutions (IFLA) (1976). Standards for Library Schools. IFLA Journal, 2(4), 209-223. 
International Federation of Library Associations and Institutions (IFLA) (2000). Guidelines for Professional Library/Information Educational Programs. Retrieved from: http://www.ifla.org/files/assets/set/publications/guidelines/ifla_educationguidelines_2000 .$p d f$

International Federation of Library Associations and Institutions (IFLA). (2012). Guidelines for Professional Library/Information Educational Programs - 2012; by K. Smith, G. Hallam \& S.B. Ghosh on behalf of IFLA's Education and Training Section. Retrieved from: http://www.ifla.org/publications/guidelines-for-professional-libraryinformationeducational-programs-2012?og $=64$

Intner, S.S., \& Vandergrift, K.E. (ed.) (1990). Library Education and Leadership: Essays in Honor of Jane Anne Hannigan. Metuchen: Scarecrow Press.

Izuagbe, R., Hamzat, S.A. \& Joseph, E.I. (2016). Electronic Information Resources (EIR) Adoption in Private University Libraries: The Moderating Effect of Productivity and Relative Advantage on Perceived Usefulness. Journal of Information Science Theory and Practice, 4(1), 30-48.

Jackson, M.M. (1981). The Usefulness of Comparative Librarianship in Relation to NonIndustrialized Countries. IFLA Journal, 7(4), 339-343.

Johnson, I.M. (2016). Foreign Interventions and Domestic Initiatives in the Development of Education for Librarianship and Information Management, with Iraq as a Case Study. (Doctoral dissertation) The Robert Gordon University, Aberdeen. 
Johnson, J.D. (2009). An Impressionistic Mapping of Information Behavior with Special Attention to Contexts, Rationality, and Ignorance. Information Processing and Management, 45(3), 593-604.

Jurow, S., \& Barnard, S.B. (ed.) (1993). Integrating Total Quality Management in a Library Setting. New York: Haworth Press.

Kaplan, R.S., \& Norton, D.P. (1992). The Balanced Scorecard - Measures that Drive Performance. Harvard Business Review, 70(1), 71-79.

Keats-Rohan, K.S.B. (2007). Prosopography Approaches and Applications: A Handbook. Oxford: Unit for Prosopographical Research, Linacre College, University of Oxford. Keresztesi, M. (1977). The Contribution of Unesco to Library Education and Training: The First 25 Years (1946-1971). (Doctoral dissertation) University of Michigan.

Khanal, N. (2012). The Lens of Postcolonial Theory in LIS Research and Practice. (Doctoral dissertation) University of Illinois at Urbana-Champaign.

Kotei, S. (1983). The Social Order, Library Service and Library Education in Africa. Botswana Library Association Journal, 5(1), 26-37.

Kotter, J.P., \& Schlesinger, L.A. (1979). Choosing Strategies for Change. Harvard Business Review, 57(2), 106-114.

Large, J.A. (1987). A Modular Curriculum in Information Studies. Paris: Unesco.

Lynch, R. (1997). Corporate Strategy. London: Pitman Publishing

Mchombu, K.J. (1986). [Statement in discussion]. In Asamani, O., et al. (Eds.) Libraries and Literacy: Proceedings of the Seventh Meeting of the Standing Conference of Eastern, 
Central and Southern African Librarians (p.198). Gaborone: Botswana Library Association..

Miwa, M., \& Miyahara, S. (ed.) (2015). Quality Assurance in LIS Education: An International and Comparative Study. New York: Springer Science and Business Media.

Neelameghan, A. (1978). Guidelines for Formulating Policy on Education, Training and Development of Library and Information Personnel. Paris: Unesco.

Ostler, L.J., Dahlin, T.C., \& Willardson, J.D. (1995). The Closing of American Library Schools: Problems and Opportunities. Westport: Greenwood Press.

Paris, M. (1988). Library School Closings: Four Case Studies. Metuchen, NJ, USA: Scarecrow Press.

Paris, M. (1991). Library School Closings: The Need for Action. Library Quarterly, 61(3), July: 259-262.

Parker, J.S. (1974). International Librarianship: A Reconnaissance. Journal of Librarianship, 6(4): 219-233.

Pettigrew, A.M., \& Whipp, R. (1993). Managing Change for Competitive Success. Oxford: Blackwell Business.

Porter, M.E. (1980). Competitive Strategy: Techniques for Analysing Industries and Competitors. New York: Free Press.

Porter, M.E. (1985). Competitive Advantage: Creating and Sustaining Superior Performance. New York: Free Press. 
Ragin, C. (1987). The Comparative Method: Moving Beyond Qualitative and Quantitative Strategies. Berkeley: University of California Press.

Roche, C. (1999). Impact Assessment for Development Agencies: Learning to Value Change. Oxford: Oxfam.

Rockart, J.F. (1979). Chief Executives Define Their Own Data Needs. Harvard Business Review, 57(2), 81-93.

Rogers, E.M. (2003). Diffusion of Innovations. $5^{\text {th }}$ ed. London: Free Press.

Saunders, W.L. (1978). Guidelines for Curriculum Development in Information Studies. Paris: Unesco.

Schatz, F., \& Welle, K. (2016). Qualitative Comparative Analysis: A Valuable Approach to Add to the Evaluator's Toolbox? Lessons from Recent Applications. Brighton: Institute of Development Studies, Centre for Development Impact. CDI Practice Paper 13. Retrieved from: http://cdimpact.org/publications/qualitative-comparative-analysis-valuableapproach-add-evaluator\%E2\%80\%99s-\%E2\%80\%98toolbox\%E2\%80\%99-lessons

Shachaf, P. (2003). Nationwide Library Consortia Life Cycle. Libri, 53(2), 94-102.

Siegrist, H. (2006). Comparative History of Cultures and Societies: From Cross-Societal Analysis to the Study of Intercultural Interdependencies. Comparative Education, 42(3): $377-404$.

Simsova, S., \& MacKee, M. (1970). Handbook of Comparative Librarianship. $1^{\text {st }}$ ed., London: Clive Bingley. 
Stieg, M. (1992). Change and Challenge in Library and Information Science Education. Chicago: ALA Books.

Tushman, M.L., Newman, W.A., \& Romanelli, E. (1988). Management of Innovation. New York: Ballinger.

Wavell, C., Baxter, G., Johnson, I.M., \& Williams, D. (2002). Impact Evaluation of Museums, Archives and Libraries: Available Evidence Project. Retrieved from The Robert Gordon University: https://www.rgu.ac.uk/4E339E80-595A-11E1BF5B000D609CB064

White, C.M. (1966). Comparative Study of Librarianship. In Bases of Modern Librarianship, pp. 13-26. New York: Macmillan.

\section{Acknowledgements}

This study was registered for a $\mathrm{PhD}$ as a member of staff at the Robert Gordon University. The resulting thesis (Johnson, 2016) includes an extensive discussion of the methodology.

One of the author's visits to Unesco was supported by the Carnegie Trust for the Universities of Scotland.

\section{Open access and copyright}

Library and Information Research is an open access journal. A freely available copy of this paper may be downloaded from the journal's website: http://www.lirgjournal.org.uk 
Library and Information Research

Volume 42 Number 1262018

Copyright and associated moral rights in works published in Library and Information Research are retained by the author(s) but this paper may be used freely, with proper attribution, in educational and other non-commercial settings. 